\title{
The study of maternal and perinatal outcome in preeclampsia in tertiary care hospital
}

\begin{abstract}
Neelima B.*
Department of Obstetrics and Gynecology, Government Maternity Hospital, Sri Venkateswara Medical College, Tirupati, Andhra Pradesh, India

Received: 15 November 2018

Accepted: 06 December 2018

*Correspondence:

Dr. Neelima B.,

E-mail: budideti77@gmail.com

Copyright: () the author(s), publisher and licensee Medip Academy. This is an open-access article distributed under the terms of the Creative Commons Attribution Non-Commercial License, which permits unrestricted non-commercial use, distribution, and reproduction in any medium, provided the original work is properly cited.
\end{abstract}

\section{ABSTRACT}

Background: Preeclampsia accounts for majority of causes for maternal and perinatal morbidity and mortality.

Methods: All patients beyond 20 weeks with pre-eclampsia admitted to Gandhi Hospital during two-year study period were enrolled in the study. The objective of this study was to analyze the type and rate of maternal and perinatal complications in preeclampsia. Women with preexisting renal disease, chronic hypertension, anemia, heart disease, epilepsy, thrombophilias, hemolytic disease, preexisting liver disease were excluded from the study. Obstetrics management was done as per existing protocol in the department. Magnesium sulphate was the drug of choice to control convulsions. Blood pressure was controlled by either tablet alpha methyl dopa or nifedipine or both. Results: Preeclampsia cases accounted for 460 (4.9\%) of total deliveries. Majority (86.52\%) were unbooked cases between $20-25$ years of age $(63.48 \%)$ and were primigravida $(60.44 \%)$ belonging to low socioeconomic status (73.91\%). Commonest maternal complication in present study was eclampsia $(34.56 \%)$ Total maternal deaths accounted for 14. Most common cause for maternal mortality was eclampsia with HELLP (9,64.28\%). Total perinatal deaths accounted for164 and most common cause for perinatal death was prematurity $(47,28.65 \%)$.

Conclusions: Preeclampsia is major leading cause for poor maternal and fetal outcome. Regular antenatal checkup , early diagnosis , early interventions, early referral to tertiary centers, optimum timing and mode of delivery and awareness among patients will reduce both maternal and perinatal morbidity and mortality.

Keywords: Maternal mortality, Preeclampsia, Perinatal mortality

\section{INTRODUCTION}

Preeclampsia complicates about 5-8 \% of all hypertensive disorders of pregnancies. ${ }^{1,2}$ As per WHO systematically reviewed maternal mortalities 2009, $16 \%$ of maternal deaths are due to hypertensive disorders of pregnancies in developed countries. $^{3}$ Preeclampsia is defined as hypertension $(\mathrm{BP} \geq 140 / 90 \mathrm{~mm} \mathrm{Hg}$ on 2 occasions 6 hours apart) appearing after 20 weeks of gestation with proteinuria. ${ }^{4}$ As Boyd stated preeclampsia remain "die Krankheit der therin" -The disease of theories. Currently accepted hypothesis includes defective placentation with abnormal trophoblastic invasion of uterine blood vessels, oxidative stress with release of vasoactive substances like oxidized LDL and Triglycerides, increased thromboxane and / or cytokines, immunological intolerance to the fetus and genetic abnormalities which trigger vascular and organ dysfunction. ${ }^{5}$

Preeclampsia is a multisystem disorder leading to many complications like Abruption, Eclampsia, HELLP syndrome, DIC, Pulmonary edema, Acute renal failure , Adult respiratory distress syndrome leading to maternal deaths. $^{6,7}$ Fetal morbidities include preterm delivery ,IUGR (intra uterine growth retardation ), still birth, low birth weight babies. ${ }^{8}$ At present there is no single cost 
effective and reliable screening test for preeclampsia and no well-established measures for primary prevention.

The ultimate treatment of preeclampsia is to deliver the fetus as early as possible to prevent maternal complications.

In some cases, it is necessary to delay the delivery in interest of the fetus to prevent prematurity and thus to reduce perinatal morbidity and mortality. Regular antenatal check-ups, careful monitoring and appropriate management are essential elements in prevention of preeclampsia deaths. ${ }^{9}$

This study is undertaken to analyse the cases of preeclampsia and to know the maternal and perinatal outcome.

\section{METHODS}

The present study is a prospective study carried out on 460 antenatal mothers beyond 20 weeks with preeclampsia and admitted to Gandhi hospital, Secunderabad, from September 2009 to September 2011.

\section{Inclusion criteria}

- All antenatal mothers meeting the criteria of Preeclampsia presenting to antenatal ward, delivery room and high-risk unit.

\section{Exclusion criteria}

- Preexisting renal disease

- Chronic hypertension

- Anemia

- Heart disease

- Epilepsy

- Thrombophilias, hemolytic disease

- Preexisting liver disease such as viral hepatitis.

National Institute of Health (NIH) Working Group on High Blood Pressure for the definitions of preeclampsia.

Preeclampsia is defined as hyper tension diagnosed after 20 weeks of gestation accompanied by proteinuria of $>3 \mathrm{~g} /$ deciliter in 24 hours urinary collection with or without edema.

All the antenatal mothers fulfilling the above criteria were enrolled for the study after taking written informed consent. On admission patients detailed demographic, obstetric, medical, personal, past and family history were taken.

General examination, systemic, abdominal and pelvic examinations were carried out for all patients. Investigations like complete blood picture, liver function tests, renal function tests, coagulation profile, fundoscopy and urine examination were done.

Ultrasound with doppler was done. Blood pressure was measured using auscultatory method with a standard calibrated instrument. An appropriately sized cuff was used to ensure accuracy. Koratkoff sound 5 was taken to measure diastolic BP. These. patients were then followed up to study the maternal and perinatal outcome. Magnesium sulphate was the drug of choice to control convulsions.

Blood pressure was controlled by either tablet alpha methyl dopa or nifedipine or both. Corticosteroids were given if the gestational age was less than 34 weeks. Obstetric management was done (spontaneous/induced labour) as per unit protocol and patients were delivered either vaginally or by caesarean section. Neonatal care was provided by pediatrician if necessary, from delivery onwards.

Uncontrolled hypertension was managed by physician. Maternal and perinatal complications were noted down. At the end of study, the data was compiled and analysed.

\section{RESULTS}

A total number of 11,992 deliveries were conducted in our hospital from September 2009 -September 2011. Of these 460 patients had preeclampsia $(3.83 \%)$.

Most of the patients having preeclampsia were unbooked $398(86.52 \%)$ belonging to low socioeconomic status $340(73.91 \%)$.

These patients were either referred from peripheral centers or the patients themselves came after development of complications. Preeclampsia was more common in primigravida $(60.44 \%)$ than multigravida $(39.56 \%)$ (Table 1).

Table 1: Distribution of socio demographic factors.

\begin{tabular}{|c|c|c|}
\hline Factor & No. of patients & Percentage \\
\hline \multicolumn{3}{|c|}{ Antenatal visits } \\
\hline Booked & 62 & 13.47 \\
\hline Unbooked & 398 & 86.52 \\
\hline \multicolumn{3}{|c|}{ Socio-economic status } \\
\hline Lower & 340 & 73.91 \\
\hline Upper & 120 & 26.08 \\
\hline \multicolumn{3}{|l|}{ Age (years) } \\
\hline$<20$ & 56 & 12.17 \\
\hline $20-25$ & 292 & 63.48 \\
\hline $26-30$ & 82 & 17.83 \\
\hline 31 and above & 30 & 6.52 \\
\hline \multicolumn{3}{|l|}{ Parity } \\
\hline Primi & 278 & 60.44 \\
\hline Multi & 182 & 39.56 \\
\hline
\end{tabular}


$46.96 \%$ patients presented with preeclampsia $>36$ weeks $43.04 \%$ patients presented with preeclampsia with gestational age between 29-32 weeks and only $10 \%$ patients presented $<28$ weeks (Table 2 ).

Table 2: Gestational age at presentation.

\begin{tabular}{|l|l|l|}
\hline Age (years) & No. of patients & Percentage \\
\hline$<28$ & 46 & 10 \\
\hline $29-32$ & 98 & 21.30 \\
\hline $33-36$ & 100 & 21.74 \\
\hline$>36$ & 216 & 46.96 \\
\hline
\end{tabular}

In the present study renal function was severely affected in preeclampsia. Blood urea $>18 \mathrm{mg} / \mathrm{dl}$ was noted in $41.30 \%$ cases. Similarly, serum creatinine $>0.8 \mathrm{mg} / \mathrm{dl}$ in $58.28 \%$ and serum uric acid $>4.5 \mathrm{mg} / \mathrm{dl}$ seen in $52.17 \%$ cases. Liver function tests were deranged in $25.64 \%$ cases of which total serum bilirubin $>1 \mathrm{mg} / \mathrm{dl}$ observed in 19.56 $\%$ cases and AST, ALT $>40 \mathrm{IU} / \mathrm{ml}$ in $6.08 \%$ cases. Severe anemia $<6 \mathrm{gm} /$ dlwas noted in 32 cases $(6.90 \%)$, reflecting blood loss due to abruptio placenta and severe platelet deficiency $<0.5 \mathrm{lacs} / \mathrm{mm} 3$ in in 12 cases $(2.60 \%)$ suggestive of HELLP Syndrome (Table 3).

Table 3: Investigations.

\begin{tabular}{|l|l|l|l|l|l|l|l|}
\hline $\begin{array}{l}\text { RFT } \\
(\mathrm{mg} / \mathrm{dll})\end{array}$ & $\begin{array}{l}\text { No. of } \\
\text { patients }\end{array}$ & LFT & $\begin{array}{l}\text { No. of } \\
\text { patients }\end{array}$ & $\begin{array}{l}\text { Hemoglobin } \\
\text { (gm/dl) }\end{array}$ & $\begin{array}{l}\text { No. of } \\
\text { patients }\end{array}$ & $\begin{array}{l}\text { Platelet } \\
\text { count } \\
\left.\text { (lacs/mm } / \mathrm{mm}^{3}\right)\end{array}$ & $\begin{array}{l}\text { No. of } \\
\text { patients }\end{array}$ \\
\hline $\begin{array}{l}\text { BU } \\
>18\end{array}$ & $190(41.30 \%)$ & $\begin{array}{l}\text { TSB } \\
(\mathrm{mg} / \mathrm{dl})>1\end{array}$ & $\begin{array}{l}90 \\
(19.56 \%)\end{array}$ & $>10$ & $248(53.91 \%)$ & $>1.5$ & 338 \\
\hline $\begin{array}{l}\text { S.Cr } \\
>0.8\end{array}$ & $268(58.26 \%)$ & $\begin{array}{l}\text { ALT, AST } \\
>40 \text { IU/ml }\end{array}$ & $\begin{array}{l}28 \\
(6.08 \%)\end{array}$ & $8-10$ & $140(30.43 \%)$ & $1-1.5$ & $68 \%$ \\
\hline $\begin{array}{l}\text { S.Ur } \\
>4.5\end{array}$ & $240(52.17 \%)$ & & & $6-8$ & $40(8.69 \%)$ & $0.5-1$ & $42(9.13 \%)$ \\
\hline
\end{tabular}

The most common maternal complication in present study was eclampsia -159 cases $(34.56 \%)$ followed by abruption - 68 cases $(14.78 \%)$ followed by Imminent eclampsia -42 cases $(9.13 \%)$ HELLP was seen in 23 (5 $\%)$ patients. 26 patients developed acute renal failure for which dialysis was required. DIC was seen in 11 (2.39\%) patients for which whole blood and fresh frozen plasma were transfused. 8 patients developed pulmonary edema. Majority of the cases were successfully managed in our hospital. In the present study 14 maternal deaths occurred. The most common cause for maternal death in present study was eclampsia with HELLP and this could probably be due to delayed referral (Table 4).

Table 4: Maternal complications.

\begin{tabular}{|l|l|l|}
\hline Complications & No. of patients & Percentage \\
\hline Eclampsia & 159 & 34.56 \\
\hline Imminent eclampsia & 42 & 9.13 \\
\hline Abruption & 68 & 14.78 \\
\hline HELLP & 23 & 5 \\
\hline DIC & 11 & 2.39 \\
\hline ARF/Oliguria & 26 & 5.65 \\
\hline Pulmonary edema & 08 & 1.73 \\
\hline Mortality & 14 & 3.04 \\
\hline
\end{tabular}

The mode of delivery was determined on the basis of fetal condition, gestational age and Bishop's score. Labor was managed based on above factors. In the present study $51.21 \%$ cases delivered vaginally and $48.69 \%$ cases delivered by caesarian section. Instrumental vaginal delivery was done either by outlet forceps or vacuum in 29 patients $(6.2 \%)$ (Table 5).

Table 5: Mode of delivery.

\begin{tabular}{|l|l|l|}
\hline $\begin{array}{l}\text { Mode of delivery } \\
\text { Spontaneous vaginal } \\
\text { delivery }\end{array}$ & 62 & 13.49 \\
\hline $\begin{array}{l}\text { Induced vaginal } \\
\text { delivery }\end{array}$ & 145 & 31.52 \\
\hline $\begin{array}{l}\text { Instrumental vaginal } \\
\text { delivery }\end{array}$ & 29 & 6.2 \\
\hline Caesarian section & 224 & 48.69 \\
\hline
\end{tabular}

The most common indication for caesarian section in the present study was fetal distress $(24.10 \%)$ followed by eclampsia $(20.53 \%)$ and then failed induction (19.64\%) (Table 6).

$218(47.39 \%)$ babies born to preeclamptic mothers had normal APGAR with immediate cry. However, 114 (24.78\%) babies required NICU admissions. Perinatal mortality was seen in 164 cases $(35.65 \%)$ of which 109 were IUD, 50 were NICU deaths and 5 were fresh still births (Table 7).

The most common cause for NICU admission in present study was prematurity followed by severe birth asphyxia. (Table 8). 
Table 6: Causes for caesarian section.

\begin{tabular}{|l|l|l|}
\hline Cause & No. of patients & Percentage \\
\hline Eclampsia & 46 & 20.53 \\
\hline Imminent eclampsia & 12 & 5.35 \\
\hline Prev. LSCS & 29 & 12.94 \\
\hline Abruption & 09 & 4.01 \\
\hline Twins & O4 & 1.78 \\
\hline Severe oligo & 11 & 4.91 \\
\hline Failed induction & 44 & 19.64 \\
\hline HELLP & 08 & 3.57 \\
\hline Fetal distress & 54 & 24.10 \\
\hline IUGR/Doppler changes & 07 & 3.12 \\
\hline
\end{tabular}

Table 7: Perinatal outcome.

\begin{tabular}{|l|l|l|}
\hline Cause & No. of babies & Percentage \\
\hline Normal APGAR & 218 & 47.39 \\
\hline IUGR & 14 & 3.04 \\
\hline NICU admissions & 114 & 24.78 \\
\hline Fresh stillborn & 05 & 1.08 \\
\hline IUD & 109 & 23.69 \\
\hline NICU deaths & 50 & 10.86 \\
\hline Total perinatal deaths & 164 & 35.65 \\
\hline
\end{tabular}

Table 8: Causes of NICU admissions.

\begin{tabular}{|l|l|}
\hline Cause & No. of babies \\
\hline Severe birth asphyxia & 34 \\
\hline Term IUGR & 02 \\
\hline Preterm IUGR & 05 \\
\hline Preterm (AGA) & 63 \\
\hline Meconium aspiration syndrome & 10 \\
\hline
\end{tabular}

\section{DISCUSSION}

Preeclampsia is a reversible multi organ disease for which delivery is the cure. It is responsible for majority of adverse maternal and perinatal outcomes. The incidence of preeclampsia and its associated complications have decreased dramatically in developed countries but not in developing countries where it still stands as one of the major complications in pregnancy. This is attributed to improvement in antenatal care, awareness among patients and proper management in developed countries. During the study period from September 2009 to September 2011 total number of preeclampsia cases were 460 . In present study $86.52 \%$ cases were unbooked and $73.91 \%$ belonging to low socioeconomic status.

This is comparable with the study done by Shaik e tal who had $82 \%$ unbooked cases $60.44,5$ of cases were primi's. Ketz et al reported $70 \%$ of cases as primi's. ${ }^{10}$ In the present study blood urea, serum creatinine and serum uric acid were abnormally elevated in $43.30 \% 58.26 \%$ and $52.17 \%$ respectively. This is comparable to study conducted by Berhe Hailemarium et al at Namibia from January 2003 to December 2004 where the values of blood urea, serum creatinine and serum uric acid were $36.98 \%, 35.62 \%$ and $29.1 \%$ respectively. ${ }^{11}$ The liver function s were deranged in $25.64 \%$ of cases whereas the study done by Saxena N et al showed that $24 \%$ of cases had deranged liver function tests. In the present study 42 out of 460 preeclampsia cases $(9.13 \%$ ) had platelets 0.5 -1.0 lakhs $/ \mathrm{mm}^{3}$ and 12 cases $(2.68 \%)$ had platelets $<0.5$ lakhs $/ \mathrm{mm}^{3}$. This is comparable with the findings of J.R. Patnaik showing $13 / 130$ patients with preeclampsia (10 $\%$ ) had platelets $0.5-1.0$ lakhs $/ \mathrm{mm} 3$ and 5/130 patients $(3.8 \%)$ had platelets $<0.5$ lakhs $/ \mathrm{mm}^{3}{ }^{12}$

In the present study eclampsia was the most common complication of preeclampsia $(34.56 \%)$ followed by abruption (14.78\%), imminent eclampsia (9.13\%), ARF/Oliguria (5.65\%) and HELLP (5\%). In a study conducted by Haddad and colleagues HELLP was the most common complication of preeclampsia (34\%) followed by eclampsia (17\%), abruption (13\%). Similar studies conducted by Hauth et al showed eclampsia was the most common complication of preeclampsia (27.4\%) followed by abruption (4\%).

There were 14 maternal deaths in present study. ${ }^{13}$ The most common cause for maternal mortality was eclampsia with HELLP syndrome. Maternal mortality rate due to preeclampsia was $1.167 / 1000$. In the present study spontaneous vaginal delivery was $13.49 \%$, induced vaginal delivery was $31.52 \%$ and caesarian section was $48.69 \%$. In a study conducted by P.N Ebeigbe from 1.3 2000-28.5. 2005 induced vaginal delivery was $48.2 \%$ and caesarian section was $52.8 \% .^{14}$ In another study conducted by Ching Ming Liu in Taiwan at Chang Gunj memorial hospital caesarian section was $48.62 \% .^{15}$ Tufnell et al reported as high as $72 \%$ caesarean section rate in BJOG.This showed that intervention in the form of induction or caeserian section was required to terminate pregnancy to prevent maternal and fetal complications.

The most common indication for caeserian section in the present study was eclampsia $(20.53 \%)$ followed by failed induction (19.64\%) and then previous LSCS (12.94\%). ${ }^{16}$ Main factors affecting perinatal mortality and morbidity were prematurity, IUGR and irregular antenatal visits. Being a tertiary care centre we have an efficient team of neonatologists and neonatal intensive care unit (NICU) back up. The perinatal mortality in ourstudy was $35.65 \%$ i.e. 164 cases of which IUD's were 109 (23.69\%), NICU deaths were $50(10.86 \%)$ and fresh still births were 5 (1.08\%). The most common cause for NICU admissions were pre-maturity $63(55.26 \%)$, severe birth asphyxia were $34(29.82 \%)$ IUGR were $7(6.14 \%)$. Shahin et al from Pakistan reported perinatal mortality of 41.6\%.Tufnell et al reported $65.3 \%$ incidence of prematurity. ${ }^{16,17}$ The high incidence of preterm delivery could be attributed to the early intervention and induction of labour or LSCS done to avert further maternal and perinatal complications. A study conducted by Hauth et al showed $14.5 \%$ cases of IUGR. Study by Imam Reza Hospital at Iran by Tavassoli Fatemeh showed $16.25 \%$ 
cases of IUGR $19.4 \%$ cases of NICU admissions. ${ }^{18}$ Study by PN Ebeigbe showed $31.9 \%$ cases of severe birth asphyxia. ${ }^{14}$

\section{CONCLUSION}

Preeclampsia still remains to be a significant cause for maternal and perinatal morbidity and mortality in developing countries. Though prevention of preeclampsia is impossible, yet its complications can be prevented. Provision of quality antenatal health care services, increasing patient awareness about warning symptoms, investigations, timely delivery and intensive monitoring in the intrapartum and postpartum period have the potential to improve maternal and perinatal outcome. Education and empowerment of women and accessible health care especially to the socioeconomically deprived and rural population is the need of the hour.

\section{ACKNOWLEDGMENTS}

Author would like to thank professor and head of Department of Obstetrics and Gynecology, Gandhi Hospital, Secunderabad. for the support during study.

Funding: No funding sources

Conflict of interest: None declared

Ethical approval: Not required

\section{REFERENCES}

1. Cunningham FG, MacDonald PC, Gant NF. Williams obstetrics. New York, NY: McGraw-Hill Professional; 2005 Mar 31.

2. Martin JA, Hamilton BE, Sutton PD, Ventura SJ, Menacker F, Kirmeyer S. Births final data for 2004. Natl Vital Stat Rep. 2009;55(1):1-101

3. Chang J, Elam-Evans LD, Berg CJ, Herndon J, Flowers L, Seed KA et al. Pregnancy related mortality in the United States , 1991-1997 Obstet Gynecol. 2003;101(2):289-96.

4. National High Blood Pressure Education Programme :Working Group Report on High Blood Pressure in Pregnancy. Am J Obstet Gynecol. 2000;183(1):S1S22

5. Taylor RN,Davidge ST, Roberts JM : Endothelial cell dysfunction and oxidative stress. In Lindheimer MD,Roberts JM, Cunningham FG (eds) : Chesley's Hypertensive Disorders in Pregnancy, 3rd ed. Elseveir, In press 2009

6. Alvarez Navascues R, Marin R. Severe meternal complications associated with pre-eclampsia : an almost forgotten pathology? Nefrologia.2001;21 (6):565-73

7. Kenni L, Baker P, Cunningham FG: Platelets coagulation and the lever, In Lidheimer MD, Roberts JM, Cunningham FG (eds): Chesley's Hypertensive disorders of pregnancy, 3rd Ed . New York , Elseveir, in Press 2009 . \& associates.

8. Singhal S, Deepika, Anshu, Nanda S. Maternal and perinatal outcome in severe pre- eclampsia and eclampsia. South Asian Fed Obstet Gynecol.2009;1(3):25-8

9. French Society of Anesthesia and Resuscitation, National College of Gynecologists and Obstetricians French. Multidisciplinary management of severe preeclampsia (PE). Experts' guidelines 2008. French Society of Anesthesia and Resuscitation. National College of French Gynecologists and Obstetricians. French Society of Perinatal Medicine. French Society of Neonatology. In Annales de Anesthesie et Reanimat. 2009;28(3)275.

10. Katz VL, Farmer R, Kuller JA. Preeclampsia into eclampsia: toward a new paradigm. Am J Obstet Gynecol. 2000;182(6):1389-96.

11. Berhe Hailemariam Woldeselassie Pre-eclampsia and its outcome (Maternal and Neonatal Morbidity and Mortality ) in the two Referral Hospitals (Windhoek Central and Katutura ), Namibia.

12. J.R. Patnaik, B.B. Pradhan, U. K. Satpathy, Arati mohanty. Platelet Estimation : Prognostic Value in Pregnancy Induced Hypertension indian J Physiol Pharacol. 2007;51(2):160-4.

13. Hauth JC, Ewell MG, Levine RL, Esterlitz JR, Sibai BM, Curet LB. Pregnancy outcomes in healthy nulliparous women who subsequently developed hypertension . Obstet Gynecol. 2000;95(1):24-8

14. PN Ebeigbe, ME Aziken Early onset Pregnancy induced hypertension / eclampsia in benin city nigeria Nig J Clinical Practice dec 2001.13(4):38893.

15. Ching Ming Liu, Po-Jen Cheng, Shuenn - Dyh Chang Maternal Complications and Perinatal Outcomes Associated with Gestational Hypertension and Severe Preeclampsia in Taiwanese Women $\mathbf{J}$ Formos Med Assoc. 2008;107(2):129-38.

16. Tufnell DJ, Jankowicz D, Lindow SW, Lyons G, Mason GC, Russell IF, et al. Outcome of severe preeclampsia/eclampsia Yorkshire 1999/2003. Br J Obstet Gynecol. 2005;112(7):875-80.

17. Shaheen B Hassan 1, Obaid M. Eclampsia, a major cause of maternal and perinatal mortality: a prospective analysis at a tertiary care hospital of Peshawar. J Pak Med Assoc. 2003;53(8):346-50

18. Fatemeh T, Marziyeh G, Nayereh G, Anahita G, Samira T. Maternal and perinatal outcome in nulliparous women complicated with pregnancy hypertension. JPMA. 2010;60(9):707.

Cite this article as: Neelima B. The study of maternal and perinatal outcome in preeclampsia in tertiary care hospital. Int J Reprod Contracept Obstet Gynecol 2019;8:285-9. 